\title{
Hemofagositik lenfohistiyositoz hastalarında kraniyal MRG bulguları
}

Cranial MRI findings in hemophagocytic lymphohistiocytosis

\author{
Cenk Eraslan ${ }^{1}$ (iD Elçin Aydın ${ }^{2}$ Elidan Maharramova ${ }^{1}$ (D) Akkız Şahin ${ }^{3}$ (D) \\ Hamiyet Hekimci Özdemir ${ }^{3}$ (iD Deniz Yılmaz Karapınar ${ }^{3}$ (iD) Cem Çallı ${ }^{1}$ OCD Ömer Kitiş $^{1}$ \\ ${ }^{1}$ Ege Üniversitesi Tıp Fakültesi, Radyoloji Anabilim Dalı, İzmir, Türkiye \\ ${ }^{2}$ Başkent Üniversitesi Tıp Fakültesi, Radyoloji Anabilim Dalı, İzmir, Türkiye \\ ${ }^{3}$ Ege Üniversitesi Tıp Fakültesi, Çocuk Sağlığı ve Hastalıkları Anabilim Dalı, Hematoloji Bilim Dalı, \\ İzmir, Türkiye
}

\section{Öz}

Amaç: Hemofagositik lenfohistiyositoz (HLH) kontrolsüz immün yanıta yol açan hiperinflamasyonla karakterize klinik bir sendromdur. Etiyolojiye bağı primer ve sekonder olarak sınıflanmaktadır. Klinik bulguları arasında ateş, splenomegali, hepatit yer almaktadır. Tanı doku örneklenmesi ile konulur. Familyal HLH'li hastaların santral sinir sistemi (SSS) tutulumu hastalığın prognozunu ve klinik gidişini olumsuz etkileyen bir faktördür. SSS tutulumunun bulguları; progresif ensefalopati, irritabilite, nöbet, kraniyal sinir paralizisi, ataksi, nistagmus, yürüme ve görme bozukluğu, psikomotor gelişim geriliğidir. Bu çalışmada, SSS tutulumu olan 6 olgunun radyolojik görüntüleme bulgularını sunmayı amaçladık.

Gereç ve Yöntem: Bir-onbir yaş aralığında 6 hasta irritabilite, nöbet, ataksi, nistagmus, yürüme ve görme bozukluğu, psikomotor gelişim geriliği gibi nörolojik bulgularla hastanemize baş vurdu ve nörolojik muayene sonrasında kranyal manyetik rezonans görüntüleme (MRG) incelemesi gerçekleştirildi.

Bulgular: Hastalarımıza klinik ve laboratuvar değerlendirmeleri sonrasında yapılan kemik iliği biyopsisi ile HLH tanısı konuldu. Hastalarımızın tamamında SSS tutulumunu gösteren kraniyal MRG bulguları saptandı. MRG incelemesinde T2 ağırlıklı ve FLAIR sekanslarında serebral hemisferlerde hiperintens odaklar ve postkontrast serilerde patolojik kontrastlanma ortak bulgular olarak belirlendi.

Sonuç: HLH hastalığının santral sinir sistemi tutulumu yüksek mortalite ve morbidite ile seyretmektedir. Kraniyal MRG SSS tutulumunu göstermede önemli rol oynamaktadır.

Anahtar Sözcükler: Hemofagositik lenfohistiyositoz, manyetik rezonans görüntüleme, santral sinir sistemi, immun.

\section{Abstract}

Aim: Hemophagocytic lymphohistiocytosis $(H L H)$ is a clinical syndrome characterized by hyperinflammation causing uncontrolled immune response. It is classified as primary and secondary according to etiology. Fever, splenomegaly, hepatitis are among the clinical findings. The diagnosis is made with tissue sampling. The central nervous system (CNS) involvement of familial HLH patients is a factor that affects the prognosis and course of the disease. The findings of CNS involvement include progressive encephalopathy, irritability, attack, cranial nerve paralysis, ataxy, nistagmus, walking and visual impairment, psychomotor development deficiency. In this study, we aimed at presenting the radiologic imaging findings of 6 cases with CNS involvement.

Materials and Methods: Six patients between the ages of 1-11 years applied to our hospital with neurological findings such as irritability, attack, cranial nerve paralysis, ataxy, nistagmus, walking and visual impairment, psychomotor development deficiency. Following the neurological examination, the cranial magnetic resonance imaging (MRI) examination was conducted.

Results: HLH diagnosis was made through bone marrow biopsy after clinical and laboratory evaluations. Cranial MRI findings indicating CNS involvement were observed in all of our patients. Hyperintense foci in cerebral hemispheres and pathological contrast enhancement in postcontrast series were defined in T2 and FLAIR sequences in MRI examination.

\footnotetext{
Yazışma Adresi: Cenk Eraslan

Ege Üniversitesi Tıp Fakültesi, Radyoloji Anabilim Dalı, İzmir, Türkiye

Makalenin Geliş Tarihi: 04.09.2016 Kabul Tarihi: 12.12.2016
} 
Conclusion: The central nervous system involvement of HLH disease is observed with high mortality and morbidity. Cranial MRI plays a significant role in revealing CNS involvement.

Keywords: Hemophagocytic lymphohistiocytosis, magnetic resonance imaging, central nervous system, immune.

\section{Giriş}

Hemofagositik lenfohistiyositoz (HLH) sitotoksik Tlenfositler ve natural killer (NK) hücrelerin fonksiyonlarında bozulma, makrofaj ve T-lenfositlerin aktivasyonu, proinflamatuvar sitokinlerin aşırı üretimi ve hemofagositoz sonucu ateş, hepatosplenomegali ve sitopeni ile karakterize hematolojik bir hastalıktır. HLH genetik ve akkiz olmak üzere iki farklı gruba ayrılır. Primer (familyal) hemofagositik lenfohistiyositoz, otozomal resesif olarak kalıtımakta ve 50.000 canlı doğumda bir görülmektedir. Primer formu erken infantlarda görülmekte olup ölümcüldür. Sekonder formu ise enfeksiyona ya da maligniteye bağlı olarak ortaya çıkabilir. Enfeksiyona sekonder olan formunun tedavisinde kemoterapi ve/veya immünsüpresif ajanlar kullanılmaktadır $(1,2)$.

HLH hastalarında santral sinir sistemi (SSS) etkilenmesi \%10-73 oranında görülmektedir. Başlıca nörolojik semptomlar; huzursuzluk, kraniyal sinir etkilenmesi, bilinç değişiklikleri, konvülsiyon ve komadır. Histopatolojik olarak etkilenme leptomeningeal bölgeden başlar, perivasküler infiltrasyon, özellikle beyaz cevheri etkileyen astrositik proliferasyon ve sonrasında gelişen nekroz alanları ve fokal demyelinizasyon ile devam eder $(1,3)$. Nörolojik bulguları olan HLH hastalarının radyolojik değerlendirmesi hastalığın tutulumunun saptanmasında önemli rol oynamaktadır.

$\mathrm{Bu}$ makalede Ege Üniversitesi Hastanesi pediatrik hematoloji kliniği tarafından izlenen, kemik iliği biyopsisi ile HLH tanısı almış hastalardan, SSS tutulumu radyolojik ve sitopatolojik olarak saptanmış olanlarının kraniyal manyetik rezonans görüntüleme (MRG) bulgularını retrospektif olarak tartışmayı amaçladık.

\section{Gereç ve Yöntem}

Ege Üniversitesi Hastanesi'nde kemik iliği biyopsisi ile HLH tanısı konmuş hastalardan nörolojik tutulum semptomları olan, radyolojik olarak SSS tutulumu düşünülen ve lomber ponksiyon ile SSS tutulumu teyit edilmiş 6 hasta çalışmaya dahil edildi. Hastaların yaşı, cinsiyeti, tanı aldığı dönemdeki yaşı, multisistemik muayene ve nörolojik semptom/bulguları kaydedildi. Tüm hastaların 1.5 Tesla MRG cihazı (Magnetom Vision, Siemens, Erlangen, Germany) ile kafa sarmalı kullanılarak elde olunmuş kraniyal MRG tetkikleri incelendi. Hastaların aksiyel-sagittal planda alınmış T1 ağırlıklı (T1-A) prekontrast, aksiyel-sagittal-koronal planda alınmış postkontrast T1 A, aksiyel T2 ağırlıklı (T2-A), koronal FLAIR sekansları ve difüzyon MRG tetkikleri retrospektif olarak nöroradyolog tarafından değerlendirildi. Tüm hastaların HLH SSS tutulumu şüphesiyle gerçekleştirilmiş ve tutulum ile uyumlu bulgular saptanmış kraniyal MRG sonrası 1-6. gün içerisindeki dönemde yapılan lomber ponksiyon işleminde elde olunan BOS (Beyin omurilik sIVISı) sitopatolojik incelemelerinde, mononükleer hücre ve protein artışı tespit edilmişti.

Tüm hastalar 18 yaşının altında olduğundan, hasta yakınları çalışma hakkında bilgilendirilerek ve imzalı onayları alındı.

\section{Bulgular}

Çalışmaya dahil edilen 6 hastanın tümü kız olup yaşları 1 ile 11 yıl arasında değişmekteydi. Hastaların ortalama yaşı 4 idi. Hastaların tanı aldıkları dönemdeki yaşları ise 8 ay ile 10 yaş arasında değişmekteydi. Hastalarda en sık izlenen semptomların ateş yüksekliği ve bilinç değişiklikleri olduğu; nistagmus, ataksi ve papil ödemin de daha nadir olarak izlendiği saptandı. MRG bulguları arasında ise tüm hastalarda her iki serebral hemisfer derin beyaz cevherde T2A-FLAIR sekanslarda yaygın hiperintens alanlar izlenmiş olup bazı hastalarda benzer patolojik sinyal intensite değişikliklerinin bazal ganglionlar düzeyinde de izlendiği görüldü. Postkontrast serilerde hastaların 3'ünde patolojik kontrastlanmanın beyaz cevher lezyonlarına eşlik ettiği görüldü (Resim-1). Bir hastada akut iskemi bulgularının da diğer SSS tutulum bulgularına ek olarak geliştiği izlendi.

Hastaların tümünde takipte gelişen nörolojik bulgular ve tanımlanan SSS tutulumunu düşündürür bulgular saptanması sonrasında lomber ponksiyon uygulandı. BOS sitopatolojik ve biyokimyasal incelemelerinde tüm hastalarda mononükleer hücre artışı izlendi. 4 hastada BOS proteininde artış vardı. Bulgular patolojik inceleme sonucunda primer hastalık infiltrasyonu ile uyumlu bulundu.

Tedavide intratekal metotreksat ve bazı hastalarda etoposid uygulandı. Hastaların 5'ine kemik iliği transplantasyonu uygulanırken, 1 hasta remisyona girmedi ve kaybedildi.

Hastaların demografik ve klinik özellikleri ile kullanılan tedavi ve MRG bulguları Tablo-1'de gösterilmektedir. 
Tablo-1. Kemik Iliği Transplantasyonu (KI Transp).

\begin{tabular}{|c|c|c|c|c|c|c|}
\hline Hasta No & $\begin{array}{c}\text { Yaş I } \\
\text { Cinsiyet }\end{array}$ & Tanı yaşı & Semptom & MRG Bulgusu & Tedavi & $\begin{array}{c}\text { Klinik } \\
\text { Seyri }\end{array}$ \\
\hline 1 & 1 yaş/K & 8 ay & $\begin{array}{l}\text { Nöromotor } \\
\text { gelişim geriliği } \\
\text { Bilinç } \\
\text { bulanıklığı }\end{array}$ & $\begin{array}{l}\text { Bilateral serebral hemisfer } \\
\text { derin beyaz cevherde T2A- } \\
\text { FLAIR sinyal intensite artımı } \\
\text { Bilateral parietooksipital } \\
\text { bölgede patolojik } \\
\text { kontrastlanma }\end{array}$ & $\begin{array}{l}\text { Intratekal } \\
\text { metotreksat } \\
\text { Prednizolon } \\
\text { KI transp. }\end{array}$ & İyi \\
\hline 2 & 2 yaş/K & 1 yaş & $\begin{array}{l}\text { Dirençli ateş } \\
\text { Bilinç } \\
\text { bulanıklığı } \\
\text { Ataksi } \\
\text { Nistagmus }\end{array}$ & $\begin{array}{l}\text { Bilateral serebral hemisfer } \\
\text { derin beyaz cevherde T2A- } \\
\text { FLAIR sinyal intensite artımı } \\
\text { Leptomeningeal yapılarda } \\
\text { patolojik kontrastlanma } \\
\text { Sağ serebral hemisfer frontal } \\
\text { ve parietal lobda akut iskemi } \\
\text { alanları }\end{array}$ & $\begin{array}{l}\text { Etoposid } \\
\mathrm{KI} \text { transp. }\end{array}$ & İyi \\
\hline 3 & 2,5 yaş/K & 2 yaş & $\begin{array}{l}\text { Dirençli ateş } \\
\text { Bilinç } \\
\text { bulanıklığı }\end{array}$ & $\begin{array}{l}\text { Bilateral serebral hemisfer } \\
\text { subkortikal alanda T2A-FLAIR } \\
\text { hiperintens patolojik } \\
\text { kontrastlanma gösteren } \\
\text { nodüler odaklar }\end{array}$ & $\begin{array}{l}\text { Intratekal } \\
\text { metotreksat } \\
\text { KI transp. }\end{array}$ & İyi \\
\hline 4 & 7 yaş/K & 5 yaş & $\begin{array}{l}\text { Dirençli ateş } \\
\text { Bilinç değişikliği }\end{array}$ & $\begin{array}{l}\text { Bilateral serebral hemisfer } \\
\text { subkortikal beyaz cevher ve } \\
\text { bilateral bazal ganglionlar } \\
\text { düzeyinde T2A-FLAIR sinyal } \\
\text { intensite artımı }\end{array}$ & $\begin{array}{l}\text { Intratekal } \\
\text { metotreksat } \\
\text { KI transp. }\end{array}$ & İyi \\
\hline 5 & 10 yaş/K & 8 yaş & $\begin{array}{l}\text { Bilinç } \\
\text { bulanıklığı } \\
\text { Nistagmus }\end{array}$ & $\begin{array}{l}\text { Bilateral serebral hemisfer } \\
\text { periventriküler beyaz } \\
\text { cevherde nodüler T2A-FLAIR } \\
\text { hiperintens odaklar }\end{array}$ & $\begin{array}{l}\text { Etoposid } \\
\text { KI transp. }\end{array}$ & İyi \\
\hline 6 & 11 yaş/K & 10 yaş & $\begin{array}{l}\text { Bilinç } \\
\text { bulanıklığı } \\
\text { Papil ödem }\end{array}$ & $\begin{array}{l}\text { Her iki serebral hemisferde } \\
\text { subkortikal beyaz cevherde } \\
\text { T2A-FLAIR sinyal intensite } \\
\text { artımı } \\
\text { Bilateral globus palliduslarda } \\
\text { T2A-FLAIR hiperintens } \\
\text { odaklar }\end{array}$ & $\begin{array}{l}\text { Etoposid } \\
\text { IVIG }\end{array}$ & Ölüm \\
\hline
\end{tabular}

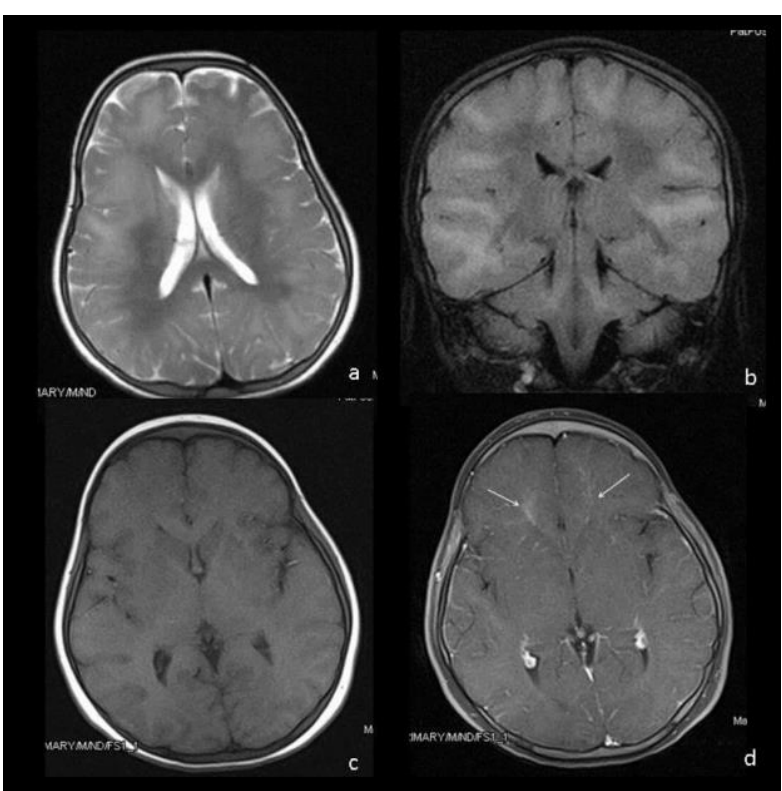

Resim-1. HLH tanılı 11 yaşında kız hasta. T2 aksiyel (a) ve FLAIR koronal (b) kesitlerde HLH santral sinir sistemi tutulumu ile uyumlu serebral parankimal sinyal intensite değişiklikleri izleniyor. Pre-kontrast (c) ve post-kontrast (d) aksiyel T1 kesitlerde bu alanlarda patolojik kontrastlanma artışları seçiliyor (ok).

\section{Tartışma}

Hemofagositik lenfohistiyositoz (HLH) ateş, hepatosplenomegali ve sitopeni ile karakterize bir hastalık olması yanı sıra nörolojik tutulum da gösterebilmektedir. Nörolojik bulgular değişken olmakla birlikte sıklıkla görülebilenler; irritabilite, ense sertliği, konvülsiyon, kraniyal sinir paralizisi, ataksi, hemipleji ve bilinç kaybıdır $(3,4)$. Henter ve ark. (3) yaptığı çalışmada HLH tanılı 23 hastanın postmortem nöropatolojik incelemesinde; makroskopik olarak sıklıkla beyinde normal ya da ödemle uyumlu görünüm izlenmiştir. Birkaç vakada ise dokuda yumuşama ve destrüksiyon sahaları göze çarpmıştır. Mikroskopik olarak normalden ileri etkilenmeye dek değişken oranlarda tutulum saptanmıştır. Meninkslerin lenfosit, histiyosit/makrofajlarla infiltre olması, perivasküler alanda infiltrasyon, parankim infiltrasyonu ve multifokal nekroz alanları sırasıyla etkilenme derecesine göre olan bulgulardır. Hastaların nörolojik semptomları ise hipotonisite, şişkin fontanel, ense sertliği, konvülsiyon, psikomotor retardasyon ve bilinç kaybı şeklinde olabilir. Beyin omurilik sıvısının (BOS) analizi artmış protein içeriği ve mononükleer hücre varlığı ile faydalı olabilir (3). Hastalarımızda da en sık görülen bulgu ateş yüksekliği 
ve bilinç bulanıklığı idi. Tümünün BOS analizlerinde mononükleer hücre artışı ve çoğunda protein artışı gözlendi.

HLH hastalarının nörolojik tutulumlarının belirlenmesinde MRG önemli bir role sahiptir. MRG ile yapılan çalışmalarda; gri ve beyaz maddedeki anormal sinyal, serebral hacim kaybına bağı ventriküllerde genişleme ve ekstraaksiyel mesafede artış, hidrosefali, atrofi, dilate subdural alanlar, kalsifikasyon ve nekroz nörolojik tutulumda gözlenebilen bulgulardır (5-7). T2-A ve FLAIR sekanslarında yüksek sinyal özelliği gösteren alanlar lenfosit ve histiyosit infiltre ettiği beyin parankim alanlar veya demyelinizasyon ile uyumlu bulunmuştur (5) Kontrastlı kesitlerde meninkslerde izlenen kontrastlanma ise lenfosit ve histiyositlerin leptomeninksleri infiltrasyonu sonucu oluşmaktadır (5). HLH'ye bağlı SSS tutulumunun kontrolü geri dönüşümsüz olan nörolojik sekellerden korunmada en önemli faktördür $(5,8)$. Özdemir ve arkadaşlarının sunduğu vakada MR spektroskopide tutulan beyaz cevherde laktat zirvesi izlenmiştir (9). Hastalarımızda MRG'de izlediğimiz ve hastalık tutulumu olarak değerlendirdiğimiz en sık bulgumuz T2-A ve FLAIR sekanslarında yüksek sinyal özelliği gösteren alanlardı. Bazı hastalarımızda postkontrast incelemede tutulum izlenen alanlarda kontrastlanma ve bazılarında ise leptomeningeal tutulumu gösteren kontrastlanma saptandı.

HLH hastalarında tedavisiz mortalite oldukça yüksek görülmektedir, bu hastalıkta erken tanı konulması, kemoterapi ve immünsüpresif tedavi verilmesi, hastalar remisyona girer girmez hematopoetik kök hücre nakli yapılması sağ kalımı arttırmaktadır. Tedavi olarak siklosporin-A yanısıra intratekal tedavide prednizolon ve metotreksat kullanımı yaygın olarak uygulanmaktadır. Sekiz haftalık başlangıç tedavisinin ardından Familyal Hemofagositik Lenfohistiyositoz hastaları ya da sekonder HLH olup dirençli seyreden veya yeniden aktive olan hastalarda tedaviye devam edilmesi, uygun donör bulunur bulunmaz hematopoetik kök hücre nakli yapılması önerilmektedir. Ailesel olmayan vakalarda ise iyileşme sağlanırsa, sekiz haftalık başlangıç tedavisi sonrasında tedavi kesilmeli ve hasta izlenmelidir. Sekonder HLH olgularında immun aktivasyona yol açan nedenin ortadan kaldırıması tedavi başarısını arttırmaktadır. Bugün için primer HLH'de kür sağlayan tedavi, kemoterapi ile hastada remisyon elde edildikten sonra allojenik hematopoetik kök hücre nakli yapılmasıdır (10-12). Hematopoetik kök hücre nakli yapıldığı sırada hastalık aktif ise sağ kalım daha düşüktür bu nedenle kemoterapötik tedavi ile hastalık kontrol altına alındıktan sonra hematopoetik kök hücre nakli yapılması önerilmektedir (10-12). Hastalık prognozu başlangıç yaşı ile ters orantılı olup, çok erken başlangıçlı vakalarda (<6 ay) mortalite daha yüksektir. SSS tutulumu da prognoz üzerine olumsuz etkisi olan faktörlerin başında gelmektedir $(10,13)$. Hastalarımızın hepsine kemoterapötik ajanlarla tedavi uygulanmıştır. Bu tedavi ile remisyona giren 5 hastamızda ise kemik iliği transplantasyonu gerçekleştirilmiştir. $\mathrm{Bu}$ hastaların izleminde de hastalığın remisyonda olduğu gözlenmiştir.

Çalışmamızın bazı kısıtılıkları bulunmaktadır. Hasta sayımızın az olması bunların başında yer almaktadır. Çalışmamızda elde ettiğimiz radyolojik bulgular literatürdeki verilerle örtüşmektedir.

\section{Sonuç}

$\mathrm{HLH}$ hastalarında santral sinir sistemi tutulumu nadir görülmekte ancak yüksek mortalite ve morbidite ile seyretmektedir. Çalışmamız sonuçlarına göre kranyal MRG bu hastaların tanısında önemli bir tanısal araç olup nörolojik semptomları olan hastaların kranyal MRG tetkikinde tanımlanan bazı bulgular hastalığın SSS tutulumunu göstermede oldukça başarılıdır. Bu konuda daha geniş serilerle yapılacak çalışmalara intiyaç duyulmaktadır.

\section{Kaynaklar}

1. Ozgen B, Karli-Oguz K, Tavil B, Gurgey A. Diffusion-weighted cranial MR. Imaging findings in a patient with hemophagocytic syndrome AJNR 2006; 27(6):1312-14.

2. Henter JI, Elinder G, Ost A. Diagnostic guidelines for hemophagocytic lymphohistiocytosis: The FHL Study Group of the Histiocyte Society. Semin Oncol 1991;18(1):29-33.

3. Henter JI, Nennesmo I. Neuropathologic findings and neurologic symptomsin twenty-three children with hemophagocytic lymphohistiocytosis. J Pediatr 1997;130(3):358-65.

4. Balcı YI, Özgürler Akpınar F, Polat A, et al. Hemophagocytic lymphohistiocytosis case with newly defined UNC13D (c.175G>C; p.Ala59Pro) mutation and a rare complication. Turk J Haematol 2015;32(4):355-8.

5. Yang S, Zhang L, Jia C, Ma H, Henter J-I, Shen K. Frequency and development of CNS involvement in Chinese children with hemophagocytic lymphohistiocytosis. Pediatr Blood Cancer 2010; 54(3):408-15.

6. Haddad E, Sulis ML, Jabado N. Frequency and severity of central nervous system lesions in hemophagocytic lymphohistiocytosis. Blood 1997;89(3):794-800.

7. Goo HW, Weon YC. A spectrum of neuroradiological findings in children with haemophagocytic lymphohistiocytosis. Pediatr Radiol 2007; 37(11):110-7. 
8. Ouachée-Chardin M, Elie C, de Saint Basile G, et al. Hematopoietic stem cell transplantation in hemophagocytic lymphohistiocytosis: A single center report of 48 patients. Pediatrics 2006;117(4):743-50.

9. Özdemir MA, Torun YA, Yıkılmaz A, Karakükcü M, Çoban D. Hemofagositik lenfohistiositozda kranial MR ve proton MR spektroskopi bulguları. Çocuk Sağlığı ve Hastalıkları Dergisi 2006;49(4): 307-11.

10. Beken B. Hacettepe Üniveristesi Tıp Fakültesi, Çocuk Hematoloji Ünitesinde izlenen familyal hamofagositik lenfohistiyositoz hastalarının değerlendirilmesi. Uzmanlık Tezi 2013.

11. Blanche S, Caniglia M, Girault D, et al. Treatment of hemophagocytic lymphohistiocytosis with chemotherapy and bone marrow transplantation: A single center study of 22 cases. Blood 1991;78(1):51-4.

12. Nespoli L, Locatelli F, Bonetti F, et al. Familial hemophagocytic lymphohistiocytosis treated with allogenic bone marrow transplantation. Bone marrow transplant 1991;7(Suppl 3):139-42.

13. Aricò M, Janka G, Fischer A, et al. Hemophagocytic lymphohistiocytosis. Report of 122 children from the International Registry. FHL Study Group of the Histiocyte Society. Leukemia 1996;10(2):197-201. 